\title{
Capitalism With Capital: A Suggested Remedy for the Absence of Investment Decision Making in Basic Microeconomics Teaching
}

Richard A. Miller

\section{Abstract}

'[U]nder competition, the rate of return on investment tends toward equality in all industries.' Introductory and intermediate microeconomics textbooks are sketchy in explaining how capital is allocated by financial markets. Capital budgeting techniques, primarily net present value, deserve a more prominent role. This article suggests ways in which financial economics can be integrated into undergraduate courses to illuminate entry into (and exit from) industries in response to profit opportunities, as an essential part of economists' narration of resource allocation in a capitalistic and dynamic market economy.

\section{Introduction}

There is no more important proposition in economic theory than that, under competition, the rate of return on investment tends toward equality in all industries. Entrepreneurs will seek to leave relatively unprofitable industries and enter relatively profitable industries, and with competition there will be neither public nor private barriers to these movements. This mobility of capital is crucial to the efficiency and growth of the economy: in a world of unending change in types of products that consumers, businesses and governments desire, in methods of producing given 
products, and in the relative availabilities of various resources - in such a world the immobility of resources would lead to catastrophic inefficiency.

George J. Stigler (1963) Capital and Rates of Return In Manufacturing Industries, NBER, Princeton University Press, p. 54

'Mobility of capital is crucial', but in our teaching we economists neglect how investment decisions are made and how capital is allocated. Textbooks in introductory economics and in intermediate price theory are remarkably sketchy in explaining the market adjustments toward long run competitive equilibrium, how 'the rate of return on investment [in the long run, under competition] tends to equality'.The texts slight (or ignore) the motivating force of the market(s) for investment in new capacity;'entry' and 'exit' in response to (economic) profit and loss receive little explanation. The short run competitive market supply curve shifts right or left with little analytic support. When we teach about capitalism we neglect firms' decisions to invest in capital projects.'In a world of unending change' in production techniques, resource availabilities and the array of available products, capital budgeting decisions on investment in new or expanded capacity assume a crucial role in resource allocation.

Examples abound. Toyota expands its Georgetown, Kentucky, plant to produce hybrid Camrys. Royal Dutch/Shell and PetroChina invest to develop an onshore natural gas field in northwest China. Airlines order and acquire hundreds of commercial aircraft from Boeing and Airbus. Proctor and Gamble builds a detergent factory; Intel invests in a chips facility; and Phelps Dodge develops a molybdenum mine. Each of these examples - automobiles, natural gas, aircraft, detergent, chips, molybdenum - involves an increase in industry capacity and an increase in quantities supplied in the respective markets. Each also involves a large expenditure now - the investment - for the prospect of future returns - the cash (in)flow. Such investment is an important part of our understanding of how resources are employed in response to consumers' preferences.

This paper provides suggestions on how well known financial economics lying behind investment decisions such as these might be integrated into introductory and intermediate courses in microeconomics. The basic capital budgeting technique is the (net) present value equation used by business firms to evaluate investments. Other capital budgeting techniques (internal rate of return, adjusted IRR, payback period, discounted payback period, profitability index) embody possible pitfalls; properly used, NPV indicates the correct accept-reject choices, and is thus analytically superior, while the other techniques may lead to incorrect choices.

The NPV equation provides links between investment decisions and long-run (tendency toward) equilibrium, between accounting and economic income 
statements (and the firm's cost curves), and between economic profit, normal profit and accounting profit. Each of those topics receives some consideration in this paper; all can receive some space in basic microeconomics teaching; and several - NPV and normal (versus accounting) profit - deserve high priority in undergraduate micro courses.

\section{Capital budgeting and net present value}

As an example of an investment opportunity and the use of the net present value technique, suppose a firm considers the following financial data to be the most likely outcome of accepting that opportunity:

\section{Investment cost: $\$ 400,000$}

Life of the investment: 4 years (with no salvage value or removal cost)

Annual sales: 10,000 units (rate of output) at a price of $\$ 50$

Direct cost per unit: $\$ 25$ (raw materials, labour, and other variable costs)

Annual overhead: $\$ 110,000$

Accounting depreciation: straight line $(\$ 100,000$ per year $)$

Financing, the financial capital necessary to undertake this project, is available (it is assumed here) at $10 \%$; the annual opportunity cost of this financial capital to those individuals and institutions providing the financing is assumed here, for simplicity, to be entirely common stock. ${ }^{1}$ The tax rate on corporate income (profit) is $25 \%$ of accounting profit. For algebraic simplicity assume that the cash flows are equal for each of the four years, that the opportunity cost of capital (10\%) remains unchanged over the life of the project, that no inventories of unsold finished goods are carried from one year to the next, and (to avoid mismatches of revenues and costs) that all cash transactions occur at the end of each year. Also assume (for analytic simplicity) that entry and exit of other firms in this industry do not take place. How does the firm evaluate this project, to decide whether to accept it (acquire the $\$ 400,000$ asset) or reject it (walk away)?

Each of the four annual pro forma accounting income statements (as an accountant would display the accounting data) would look like this:

$\begin{array}{lrl}\text { Sales revenue } & \$ 500,000 & (10,000 \text { units @ \$50) } \\ \text { Direct cost } & -250,000 & (10,000 \text { units @ \$25) } \\ \text { Overhead cost } & -110,000 & \\ \text { Depreciation } & \frac{-100,000}{40,000} & (\$ 400,000 / 4) \\ \text { Income before tax } & \frac{-10,000}{30,000} & (\text { tax rate } t=.25 \times \text { income before tax }) \\ \text { Tax } & \end{array}$


The annual cash flow from this opportunity is thus projected to be $\$ 130,000$ ( $\$ 100,000$ of accounting depreciation, an accounting cost but not a cash outflow, plus $\$ 30,000$ of income - accounting profit - after tax) the bottom line. And depreciation appears in the accountant's income statement primarily to allow the accurate calculation of income taxes). This entire annual cash flow could be returned each year to the suppliers of financial capital, if the firm has no other investment opportunities that are expected to earn at least the $10 \%$ cost of financial capital. In practice, of course, some of the cash flow is usually returned to the suppliers of financial capital as dividends, interest and/or stock repurchases, but the majority (not paid out) is retained in the firm to finance further investment including the possible replacement of some worn out capital assets. ${ }^{2}$

Is this opportunity financially worthwhile, ie will it earn (or more than earn) the $10 \%$ opportunity cost of capital? Will accepting the project add to the owners' wealth? The $\$ 400,000$ investment returns a cash flow, $\$ 130,000$ per year for four years. Discounted at the cost of capital, the net present value of this stream of future values is

$\mathrm{NPV}=-\$ 400,000+\frac{\$ 130,000}{(1.10)}+\frac{\$ 130,000}{(1.10)^{2}}+\frac{\$ 130,00}{(1.10)^{3}}+\frac{\$ 130,000}{(1.10)^{4}}$

or $\mathrm{NPV}=-\$ 400,000+\sum_{T=1}^{4} \frac{\$ 130,000}{(1.10)^{T}}=\$ 412,082.51-\$ 400,000=\$ 12,082.51$

Based on these estimates, the project should be accepted; the positive NPV suggests that the investment is expected to produce an addition to the owners' wealth. The investment will produce an annual return expected to exceed the $10 \%$ opportunity cost of financial capital. ${ }^{3}$ The ratio of present value of future cash flows to the reproduction cost $(\$ 412,082.51 / 400,000=1.03)$ is of course Tobin's q; it is also the profitability index.

How might the pro forma accounting income statement be reformed to reflect the economic concepts (all annual) of total revenue, variable costs, fixed costs and (economic) profit? This reformulation requires the calculation of normal profit, the annual cash flow necessary to return exactly the $10 \%$ cost of capital. This calculation requires the use of the NPV equation: setting NPV $=0$, with the annual (and equal) cash flow (not the NPV) as the algebraic 'unknown:

$$
\mathrm{NPV}=0=-\$ 400,000+\sum_{T=1}^{4} \frac{C F}{(1.10)^{T}}=-\$ 400,000+C F\left[\frac{1-(1.10)^{-4}}{.10}\right]
$$

Solving, $C F=\$ 126,188.32$, the annual normal profit - an economic cost - is less than the $\$ 130,000$ estimated annual cash flow by $\$ 3,811.68$, the estimated annual supranormal or economic profit. The pro forma economic income statement for each of the four years, using conventional economic terms and presuming that $\mathrm{Q}=10,000$ per year, is: 


$\begin{array}{lrl}\text { Total revenue } & \$ 500,000 & (10,000 \text { units @ \$50) } \\ \text { Variable cost } & & \\ \text { Labour, raw materials } & -\$ 250,000 & (10,000 \text { units @ \$25) } \\ \text { Tax } & -\$ 10,000 & (25 \% \text { of accounting income before tax })\end{array}$

Fixed cost

Overhead cost

Normal profit

Economic profit
$-\$ 110,000$

$-\$ 126.188 .32$

$\$ 3,811.68$

$$
\begin{aligned}
& A V C=\frac{\$ 260,000}{10,000}=\$ 26.00 \\
& A F C=\frac{\$ 236,188.32}{10,000}=\$ 23.62 \\
& A T C=\frac{\$ 496,188.32}{10,000}=\$ 49.62
\end{aligned}
$$

Economic profit per unit is $\frac{\$ 3,811.68}{10,000}=\$ 0.38$

Tax is a variable cost because an alteration in the rate of output (more than or less than 10,000 units per year) will alter the annual tax; if few enough units are sold per year the accounting profit and thus the tax will become zero. Normal profit is a cost once the asset has been acquired and financed (both for $\$ 400,000$ ). The present value of the four years' annual economic (or supranormal) profit, discounted at $10 \%$, is $\$ 12,082.51$, the increase in owners' wealth at $\mathrm{T}=0$ when the project is accepted.

Figure 1 represents the standard, $U$-shaped cost curves (as these unit cost curves appear in virtually all introductory and intermediate micro texts ${ }^{4}$ ) for a firm in a perfectly competitive industry. AFC includes the cost of normal profit (plus other fixed costs); ATC includes all costs, fixed and variable, including (also) the cost of normal profit or (as the textbooks put it) including the necessary return to capital.

\section{Financing and an efficient stock market}

What happens to the value of this firm's shares of stock? Presume, now: (1) that this firm is newly established, that the firm has no other assets or liabilities or net worth and thus is financed by an initial public offering (IPO) of common stock specifically to undertake this project, and that flotation costs are zero; (2) that all the cash flow will be returned (when earned at the end of each year) to the stockholders; (3) that no other firm enters the industry, ie barriers to entry prohibit any (further) expansion of industry capacity; and (4) that the firm will be killed off when the assets become worthless at $\mathrm{T}=4$. 
Figure 1.

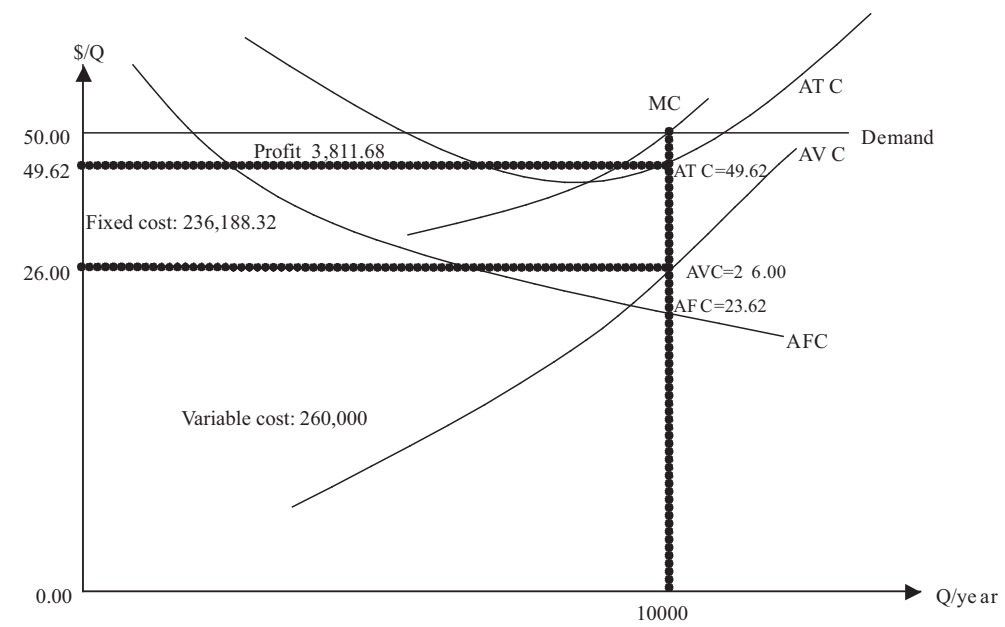

Suppose that 5,000 shares of common stock are sold at a price of $\$ 80$ per share to raise the necessary financing of $\$ 400,000$. Once the assets are acquired (at $\mathrm{T}=0$ ) and knowledge of this new firm becomes known the price will quickly be bid up (the efficient market hypothesis). How high? The present value of the cash flow on which all shareholders have a claim is $\$ 412,082.51$. The price of one share, thus, is

$$
\frac{\$ 412,082.51}{5,000}=\$ 82.42 \text {. }
$$

At this price, the owners will receive exactly $10 \%$ on their shares: the CF per share per year is $\$ 130,000 / 5000=\$ 26$, so the present value (price) of one share is

$$
\sum_{T=1}^{4} \frac{\$ 26}{(1.10)^{T}}=\$ 82.42 \text {. }
$$

As four years pass, the price fluctuates; it rises during the first year (as the cash flow comes nearer) to reach $\$ 26+\sum_{T=1}^{3} \frac{\$ 26}{(1.10)^{T}}=\$ 90.66$ just before the first $\$ 26$ is paid.

Then at $\mathrm{T}=1$ just after the first $\$ 26$ is paid out the share price falls to $\$ 64.66$, which is the discounted value (at $10 \%$ ) of the remaining three payments of $\$ 26$. At T $=2,3$, 4 (just after the second, third and final $\$ 26$ payments are made) the price is successively $\$ 45.12, \$ 23.64$ and zero. Based on the initial market price of $\$ 82.42$ (not the $\$ 80$ IPO price) the owner of one share has earned precisely $10 \%$ per year on the value of that one share. 


\section{Depreciation}

Depreciation is the recognition that as time passes and the asset is used the value of the asset declines. In accounting terms depreciation is an expense (a cost on the accounting income statement) but not an expenditure (ie not an outflow of cash - the original investment expenditure has already counted the cash outflow).The decline in value (book or economic) will be slower the longer the life of the asset; if the asset never wears out, depreciation may be zero. However technical change and shifts in demand for the product may require some economic (and accounting) depreciation.

Accounting depreciation reduces the book value (accounting value) of assets to reflect their finite life, and is based on the original or historical cost, the expected (finite) life, the salvage value or removal cost at the end of its life, and the method of depreciation employed by the accountants and allowed by the Internal Revenue Service. In this example the accounting depreciation of $\$ 100,000$ per year by the straight-line method is arbitrary and simplifies the calculations; various other accounting schedules have been used, generally accelerated so that accounting depreciation is greater in the earlier years (and taxes smaller) compared with later years. Accelerated depreciation thus accelerates the cash flow and hence increases the NPV at the time the potential investment is evaluated, $T=0$.

Economic depreciation of this physical asset can be inferred from the declining value of the NPV as time passes (Hulten, 1990). At the end of one year, three $\$ 130,000$ amounts remain after the first year's $\$ 130,000$ is received by the firm (and paid out to shareholders or retained for further investment which passes the NPV > 0 criterion).

Its NPV at $10 \%$ is $\sum_{T=1}^{3} \frac{\$ 130,000}{(1.10)^{T}}=\$ 323,290.76$.

The economic value of this asset has declined by $(\$ 412,082.51-\$ 323,290.76)=$ $\$ 88,791.75$; this is the economic depreciation of the first year. Similar calculations produce the following depreciation schedule:

$\begin{array}{lll}\text { End of T } & \text { Value at T } & \text { Economic depreciation during } T \\ 0 & \$ 412,082.51 & \\ 1 & \$ 323,290.76 & \$ 88,791.75 \\ 2 & \$ 225,619.83 & \$ 97,670.93 \\ 3 & \$ 118,181.82 & \$ 107,438.01 \\ 4 & 0 & \$ 118,181.82 \\ \text { Total depreciation } & & \$ 412,082.51\end{array}$


This mirrors exactly the decline in the share price as the asset ages; dividing the annual values by the number of shares (5000) produces the decline in the share price, from $\$ 82.42$ to $\$ 64.44$ to $\$ 45.12$ to $\$ 23.64$ to zero, as indicated earlier.

\section{Capital Budgeting and the Internal Rate of Return}

This investment opportunity is projected to return more than the $10 \%$ cost of capital, since NPV is positive. How much more, in per cent? This is a frequently asked, and sometimes misunderstood, question. The NPV equation, with the discount rate as the unknown, provides the answer, known as the internal rate of return:

$$
\mathrm{NPV}=0=-\$ 400,000+\sum_{T=1}^{4} \frac{\$ 130,000}{(1+r)^{T}} \Rightarrow r \approx 11.388 \%
$$

This algebraic solution (the IRR) is the annual rate of return, in cents per dollar per year, paid (by the firm as the acquirer of financial capital) and received (by the owners as suppliers of financial capital) on the remaining or outstanding or unpaid off balance of the funds. The cash flow of $\$ 130,000$ is returned to the owners each year. Part of this annual payment is the rental cost of funds, the IRR cost of $11.388 \%$ applied to the principal outstanding (unpaid off), and part is a return of some portion of that remaining balance or principal. As the original funds are repaid, the rental portion decreases and the repayment portion increases.

To see how this works:

$T$

Cash flow

Rental cost at

$11.388 \%$ on the

remaining balance

Return of original

financial capital

Remaining balance
1

130,000

45,552

84,448

$94,064.94$

$104,777.05116,709.06$

130,000

3

4

$S$

130,000

130,000

520,000

$35,935.06$

$25,222.95$

$13,290.94$

$120,000.95$
$0.95 \approx 0$

The original owners have earned, and the firm has paid, $11.388 \%$ on the remaining balance of the funds. Since the expected IRR $=11.388 \%$ exceeds the $10 \%$ cost of capital, this is an attractive potential investment. ${ }^{5}$

The IRR suggests an approach to the market demand for (financial) capital. At any time (or in any year) there exist a number of investment opportunities in the economy. Arrayed in decreasing IRR, which is measured by an interest rate, these investment opportunities provide the demand schedule, with the IRR (as the 
interest rate) on the $y$-axis and the prospective investment expenditures accumulated, as the IRR declines, on the $x$-axis. The market supply schedule of financial capital is a standard (horizontal, then upward rising) supply curve with the cost of capital (an interest rate) also on the $y$-axis. The intersection of the IRRdemand schedule and the opportunity cost of funds - the supply schedule provides the equilibrium market interest rate and the amount of (annual) investment expenditures, which are all projects for which NPV $>0$ at the (marginal) cost of capital. Restrictive monetary policy raises the supply schedule of funds and thus raises the equilibrium cost of capital, reducing investment: loose monetary policy that lowers interest rates and the cost of capital stimulates investment.

\section{Entry and exit: the competitive long run}

Capital mobility will differ across industries, between the extremes of absolutely blockaded entry and contestability. Barriers to entry (BTE) are impediments to capital mobility in response to profit opportunities, thus a BTE is any market condition or strategic behaviour by incumbents (or the government) that slows (or prevents) the long-run adjustment process. No agreement has emerged on a single definition of BTE, but examples include licensing, intellectual property (patents, copyrights, trade secrets), control of essential resources (eg Alcoa's control of bauxite before World War II), strategic behaviour (limit pricing, bundling, price discrimination, raising rivals' costs) and Bain's original barriers (scale economies and sunk costs, absolute cost advantages of incumbents, product differentiation) (Gilbert, 1989). No one requires that entry be instantaneous; construction of a new plant takes time (after the entrant recognises the opportunity), and even shifting an existing airplane from route $A$ to route $B$ (the original example of contestability) can hardly be accomplished overnight. Capital budgeting and NPV nevertheless provide the rationale for capital mobility, whether slowed by the BTE or not.

This example assumes (so far) that market conditions remain unchanged for four years, that the $\$ 130,000$ annual cash flow neither falls nor rises and that $11.388 \%$ is paid and earned for the life of the physical assets. The rate of return to this firm in its industry exceeds the rate of return in other industries; $10 \%$ money (financing) is chasing a $11.388 \%$ investment opportunity. The 'rate of return on investment' has not tended 'toward equality in all industries.' Entry is blockaded.'Under competition', when entry is free and the market is contestable so other firms will enter in response to the profit opportunity, industry output will increase and market price will fall, will drive down (over time) the rate of return below $11.388 \%$. Further entry, of course, ceases to be attractive when the return has fallen to $10 \%$, the opportunity cost of capital. 
To see how capital and other resources are allocated into this industry, assume that entry is free, ie there are no barriers to entry of new firms (or the expansion of incumbent firms) and that new entrants enjoy no advantages in cost or technology. Assume, too, that firms in this industry face infinitely elastic supplies of factors so input prices do not rise with expansion of the industry capacity and output, and that product differentiation is absent. Also assume a perfectly competitive product market, so all suppliers are price takers. With the representative incumbent firm earning over $11 \%$ on capital investment entry will produce an expansion of industry output, a reduction in incumbent firms' output and a fall in the common (industry) price. (Which firm, among these perfectly competitive price-taking firms, first lowers its price is a question the theory does not address.)

Profit will fall; in long-run competitive equilibrium economic profit will vanish and the rate of return to capital will fall to the cost of capital, here $10 \%$ per year. For a representative firm presume: (1) that its output per year falls to 9,000 (vice 10,000); and (2) that the minimum of the U-shaped ATC is $\$ 49.60$ at that new output. In long-run competitive equilibrium the accounting and economic income statements for this firm will look as follows: (The numbers are consistent with those in the two prior, non-long run equilibrium income statements earlier, as well as the general shapes of the unit cost curves; ATC and AVC have positive slopes in the range $9,000 \leq Q \leq 10,000$, while $A F C$ has a negative slope.)

Income statements

(long-run competitive equilibrium)

$\begin{array}{llr}\text { Accounting } & \mathrm{Q}=9,000, \mathrm{P}=\mathrm{AVC}=49.60 \\ \text { Sales revenue } & \$ 446,400.00 \quad(9,000 \times 49.60) \\ \text { Direct cost } & -201,482.24 \\ \text { Overhead } & -110,000.00 \\ \text { Depreciation } & \underline{-100,000.00} \\ \text { Income before tax } & \$ 34,917.76 \\ \text { Tax } & \underline{8,729.44} \\ \text { Income after tax } & \$ 26,188.32 \\ & \mathrm{CF}= & \$ 126,188.32\end{array}$


International Review of Economics Education

\section{Economic}

Total revenue

$\$ 446,400.00$

Variable cost

Direct

201.482.24

$\operatorname{Tax}$

$8,729.44$

$\underline{-\$ 210,211.68}$

Fixed cost

Overhead

110,000

Normal profit

$126,188.32$

$-\$ 236,188.32$

Economic profit

0

$\mathrm{AVC}=\frac{210,211.68}{9,000}=\$ 23.36$

$\mathrm{AFC}=\frac{236,188.32}{9,000}=\$ 26.24$

$\mathrm{ATC}=\frac{446,400}{9,000}=\$ 49.60$

Economic profit per unit $=\frac{0}{10,000}=0$ at $\mathrm{P}=\$ 49.60$

Figure 2.

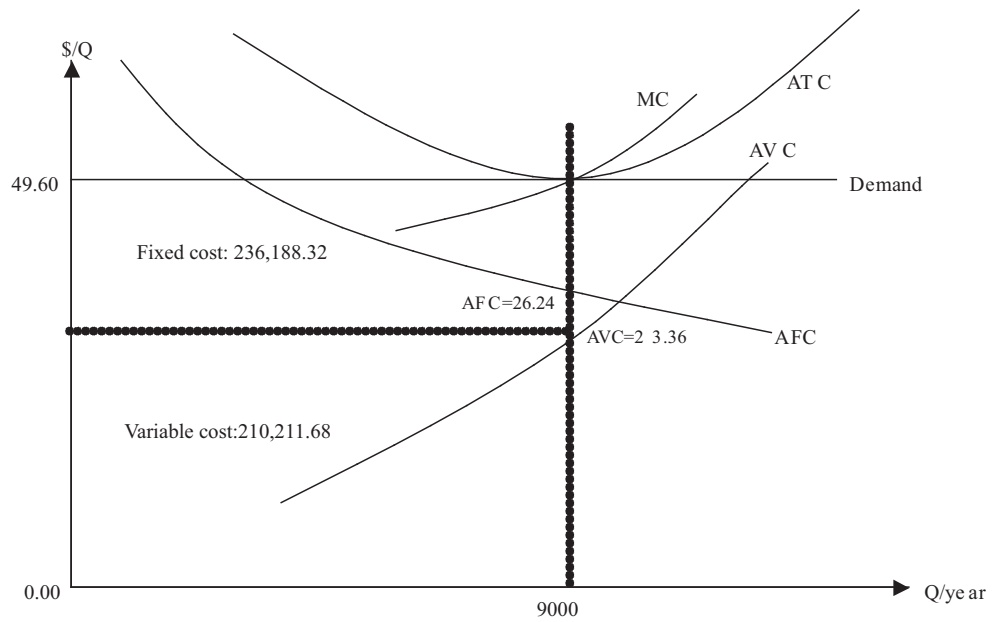


Figure 2 represents the cost curves for a representative firm in long-run competitive equilibrium, after the adjustments wrought by entry have been completed. For the industry (market), output (with entry and expansion of capacity) has increased. Price has fallen to $\$ 49.60$, the minimum ATC that includes all costs 'including the necessary return to capital' (10\% per year), the $\$ 126,188.20$ of annual normal profit. This firm has reduced its annual output from 10,000 to 9,000. Economic profit has been competed away. Capital budgeting has drawn capital (and labour and raw materials and...) into this industry from other less profitable activities; resources have been reallocated in response to profit opportunities. The rate of return on investment has tended toward equality as the $11.388 \%$ opportunity has fallen to the $10 \%$ cost of capital. Of course, any barriers to entry - barriers to the mobility of capital investment - will slow, perhaps stop (for a while) this reallocation process. ${ }^{6}$

\section{Remain in operation?}

'Normal profits. That minimum amount of profit [ie cash flow] which a firm must acquire in order to induce the firm to remain in operation. This is where all opportunity costs are just covered by total revenue and therefore corresponds to a zero level of [economic] profits.'

David W.Pearce (Ed.) (1992) The MIT Dictionary of Modern Economics, 4th edn., The MIT Press, p. 310

At long-run competitive equilibrium, with annual (4 years) cash flow of $\$ 126,188.32$ producing a $10 \%$ rate of return on a $\$ 400,000$ investment will the firm choose 'to remain in operation'? Of course the firm (at $\mathrm{T}=4$ ) may repeat the process of acquiring the funds (through a follow-on stock offering or secondary offering) to replace the now worn out (and worthless) original assets; this would be necessary if the entire cash flow had been paid out each year as it had been received, as was assumed above. Exact replacement of the physical assets presumes that market conditions (demand, technology, factor prices) are the same at $\mathrm{T}=4$ as at $\mathrm{T}=0$.

Alternatively the annual cash flow can be considered in two parts: (1) the annual opportunity cost on the $\$ 400,000,10 \%$ or $\$ 40,000$ per year paid annually to the owners as a rental fee on the funds; and (2) the remainder $(\$ 126,188.32-\$ 40,000=$ $\$ 86,188.32$ ) retained in the firm and invested in some other opportunity to earn the firm's $10 \%$ cost of capital. If the firm cannot earn (at least) $10 \%$ on this retained cash flow, it should be returned to the owners who can earn $10 \%$ elsewhere. Will this second part (the $\$ 86,188.32$ per year for four years earning exactly $10 \%$ per year) accumulate to an amount that will allow the firm 'to remain in operation' in the long run by replacing the assets at $\mathrm{T}=4$ (or if it so decides, to return the original amount to the suppliers of the financial capital)? What is that future value? It is 
$\$ 86,188.32\left[(1.10)^{3}+(1.10)^{2}+(1.10)^{1}+(1.10)^{0}\right]=\$ 86,188.32\left[\frac{(1.10)^{4}-1}{.10}\right]=\$ 400,000$. The firm can, at $\mathrm{T}=4$, use the $\$ 400,000$ either to replace the now worthless original assets with an identical investment (if at $\mathrm{T}=4$ the NPV $\geq 0$ ), or to return the principal amount to the original suppliers of the financial capital. The annual normal profit of $\$ 125,188.32$ is just adequate 'to induce the firm to remain in operation' by replacing the worn out assets at $\mathrm{T}=4.7^{7} \mathrm{Or}$, if the (re)investment is no longer attractive (NPV $<0$ at T $=4$ ), returning the $\$ 400,000$ to the suppliers of capital (if indeed it has been earned and reinvested during the period $T=0, \ldots 4$ ) or invested in another different project at $\mathrm{T}=4$ with NPV $>0$.

The long-run equilibrium indicated in Figure 2 and the corresponding economic income statement, where economic profit is zero, represents the long-run economic breakeven point. A lower price (than \$49.60) would not return the necessary cash flow for the firm to remain in operation: it would shut down, at least this activity, and perhaps go into a different line of business.

Accountants would support a different long-run breakeven point, where accounting profits are zero. The accounting breakeven is defined as follows: sales revenue less direct (variable) costs less taxes must cover the fixed costs of depreciation and overhead, presumably at a rate of output less the 9,000 and a price below $\$ 49.60$. In this example income after tax is $\$ 26,188.32$. The firm is more than breaking even in an accounting sense.

A firm's short-run shut-down point, where the firm will cease production and exit the market, before those assets are 'worn out' but are economically worthless, occurs when the cash inflow from sales revenue is inadequate to cover the cash outflow from direct (variable) costs. If this cash flow (revenues less direct or variable costs) is positive, then the firm will continue to produce; its (positive) cash flow from operations will make at least some contribution to paying the fixed (cash flow) costs.

\section{Conclusion}

Stigler properly emphasised the tendency under competitive conditions for the rate of return to approach equality across industries, an equality which characterises long-run competitive general equilibrium emphasised in microeconomics texts. Two sorts of influences modify this tendency. First, competitive conditions may not prevail; entry barriers (including exit barriers) may slow, or for a time halt, investment and the expansion of capacity in response to profit opportunities. Monopolists may - for a time, perhaps an extended time - earn supranormal profit, rates of return above their costs of capital. 
Second, market economies are better characterised by recognising their dynamic elements of innovative change - new products, new techniques - rather than by emphasising competitive general equilibrium. Production techniques will improve, new sources of inputs will emerge, new products will be developed and offered, and consumer's tastes may change. Alterations in supply and demand conditions will affect the rates of return and thus modify the capital budgeting calculations - Stigler's'world of unending change in types of products..., in methods of produc[tion]..., and in the availabilities of various resources....' In such an Austrian economy buffeted by the Schumpeterian perennial gale of creative destruction, equilibrium (market or general) is elusive, a moving target, and capital budgeting deserves still greater importance in economists' narration of how resources are allocated.

Students in courses in basic microeconomics deserve some discussion of these issues of NPV, normal (versus accounting) profit, and rates of return. Virtually all introductory and intermediate micro texts give short shrift to these issues, thus denying students an exposure to a fundamental mechanism in a market economy. We teach capitalism with out discussing capital; students deserve better.

\section{References}

Brealey, R A. and Myers, S. C. (1996) Principles of Corporate Finance, 5th edn., New York: McGraw-Hill.

Gilbert, R.J. (1989) 'Mobility Barriers and the Value of Incumbency' in R. Schmalensee and R. D.Willig (Eds) Handbook of Industrial Organization, Vol.,l, Amsterdam: North-Holland.

Hulten, C. R. (1990) Amortization in The New Palgrave: A Dictionary of Economics, New York:W.W. Norton \& Co.

Miller, R. A. (2000) 'Ten Cheaper Spades: Production Theory and Cost Curves in the Short Run', Journal of Economic Education, Vol. 31, pp. 119-130.

Miller, R. A. (2006) The Weighted Average Cost of Capital is Not Quite Right, forthcoming. Ross, S. A., Westerfield, R.W. and Jaffe, J. (2005) Corporate Finance, 7th edn., New York: McGraw-Hill Irwin.

\section{Notes}

1 When a firm uses more than one source of financial capital (bonds and preferred stock in addition to common stock) the cost of capital is a weighted average of the costs of the individual components. For a critique of the commonly used weighted average cost of capital, see Miller (2006).

2 Some firms carry what appears to be excess cash; Microsoft has about $\$ 30$ billion of cash on its balance sheet, and has only recently started to pay a modest cash dividend. For the business sector more generally, over the past 20+ years internal financing has provided between $62 \%$ and $100 \%$ of investment expenditures (capital spending and net working capital) (Brealey and Myers, 1996: 366-367; Ross, Westerfield, and Jaffe, 2005:395). Internal financing, of course, should pass the NPV test; if it doesn't, then the suppliers of finance have better opportunities. That's what the $10 \%$ opportunity cost is all about. Microsoft? Who knows. 
3 Present value (discounting a future value to the present) is a difficult concept for many beginning economics students. One way to introduce the concept is to start with compound interest (calculating a future value given the known present value and growth rate); most students have bank accounts earning interest and have had exposure to compounding in Algebra 1. Then switch the algebraic unknown from the future value to the present value and solve the equation for PV. Finally apply the general formula to a series of future values.

4 Empirical analysis reveals that cost curves for real firms most likely possess a different shape: AVC (or average direct cost) is often horizontal, and marginal cost and average direct cost are equal and horizontal in the short run. However, the theory that produces rising marginal and average variable costs - diminishing marginal productivity - confuses the stock of capital with the flow of services from that capital stock. For a discussion and a reconciliation of the empirics and the theory, see Miller (2000).

5 The IRR is the solution to an algebraic equation, no more, no less. Its economic content is the return on the remaining balance (the unpaid-off balance), as the table illustrates. The IRR so interpreted is easier for students to grasp than the criticism that the IRR implicitly assumes the reinvestment of the cash flow of the IRR.

6 This example of a firm in a perfectly competitive industry can easily be modified to reflect monopolistic competition (product differentiation with free entry in the substitutional neighbourhood). The Chamberlinian tangency (long run) displays zero economic profit.

7 Inflation (or deflation) can hit the reproduction cost of that asset. If the asset is more (or less) expensive at $\mathrm{T}=4$ that it was at $\mathrm{T}=0$ (with no change in its productivity), then the annual $\$ 86,118.32$ invested at $10 \%$ will be inadequate (or more than adequate) to replace that asset when it wears out. For example, if the price (the cost of acquiring the same asset new) of that asset rises at $3 \%$ per year, its acquisition at $T$ $=4$ would require an investment of expenditure of (about) $\$ 450,000$. The necessary annual cash flow would then be $\$ 76,276.66$.

\section{Acknowledgements}

I am indebted to Benjamin Byers, Abigail Hornstein, Madeleine Howenstine, Manolis Kaparakis, Andrew Perechocky, Jonathan Siegelaub, Gilbert Skillman and the anonymous referees for comments on and help with various versions of this material. I am also grateful for financial support from the Woodhouse/Sysco Professorship research funds.

\section{Contact details}

Richard A. Miller

Department of Economics

Wesleyan University

Middletown CT 06459

USA

Tel: $\quad 860-685-2354$

Fax: $\quad 860-685-2301$

Email: ramiller@wesleyan.edu 